\title{
Is there a role for telediastolic dimensions of the $L V$ as an estimate of preload in non-critical patients? A study in volunteers.
}

\author{
Daniel Rodrigues Alves (Anaesthesiology resident) \\ Centro Hospitalar de Lisboa Ocidental, Lisbon, Portugal; Head of Department: Manuel Chedas
}

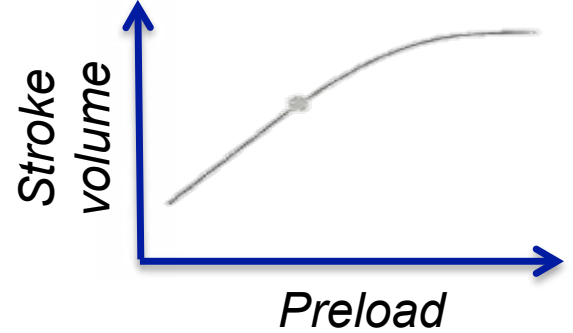

Figure 1 - Frank-Starling curve.
Background and Goal of Study: Estimating fluid responsiveness ${ }^{1}$ has been established as an important landmark in fluid therapy, and several indices were developed with such in mind. Presently dynamic preload indices gain ground, but many professionals once relied to some extent on static parameters such as telediastolic dimensions of the LV2, namely at short axis views. We decided to assess their usefulness by comparing such parameters with the individual's fluid responsiveness state - as defined by an appropriate aortic VTI variation with the passive leg raise manoeuvre (var $\left.\mathrm{VTI}_{\mathrm{Ao}_{0}} \mathrm{PLR}\right)^{3}$.

\section{Materials \& Methods:}

- Observational, analytic study

- 31 volunteers enrolled, each of which was examined by TTE on two distinct occasions

$$
\begin{aligned}
& \text { - 16F:15M } \\
& \text { - 26-67 years old } \\
& \text { - No cardiac comorbidities }
\end{aligned}
$$

- 62 echocardiograms performed (GE Vivid $7^{\circledR}$ ), using the Passive Leg Raise (PLR) manoeuvre

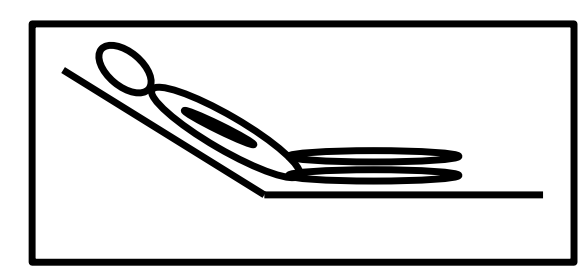

Basal state

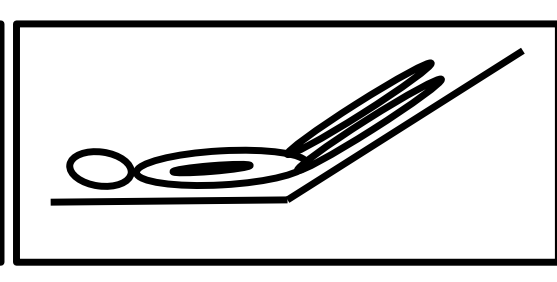

Passive leg raise
Figure 2 - Classical examination suplemmented using the PLR manoeuvre.

\section{- Study variables}

- LV telediastolic diameter in PSLAx view (and use of the Teicholz formula)

- LV telediastolic area at the papillary muscles level in PSSAx view

\section{- $\Delta V T I_{A o} P L R$}

- $\quad \Delta \mathrm{VTI}_{\mathrm{Ao}} \geq 10-15 \%=>$ fluid responsive

- $\Delta \mathrm{VTI}_{\mathrm{Ao}}<10-15 \%=>$ not fluid responsive
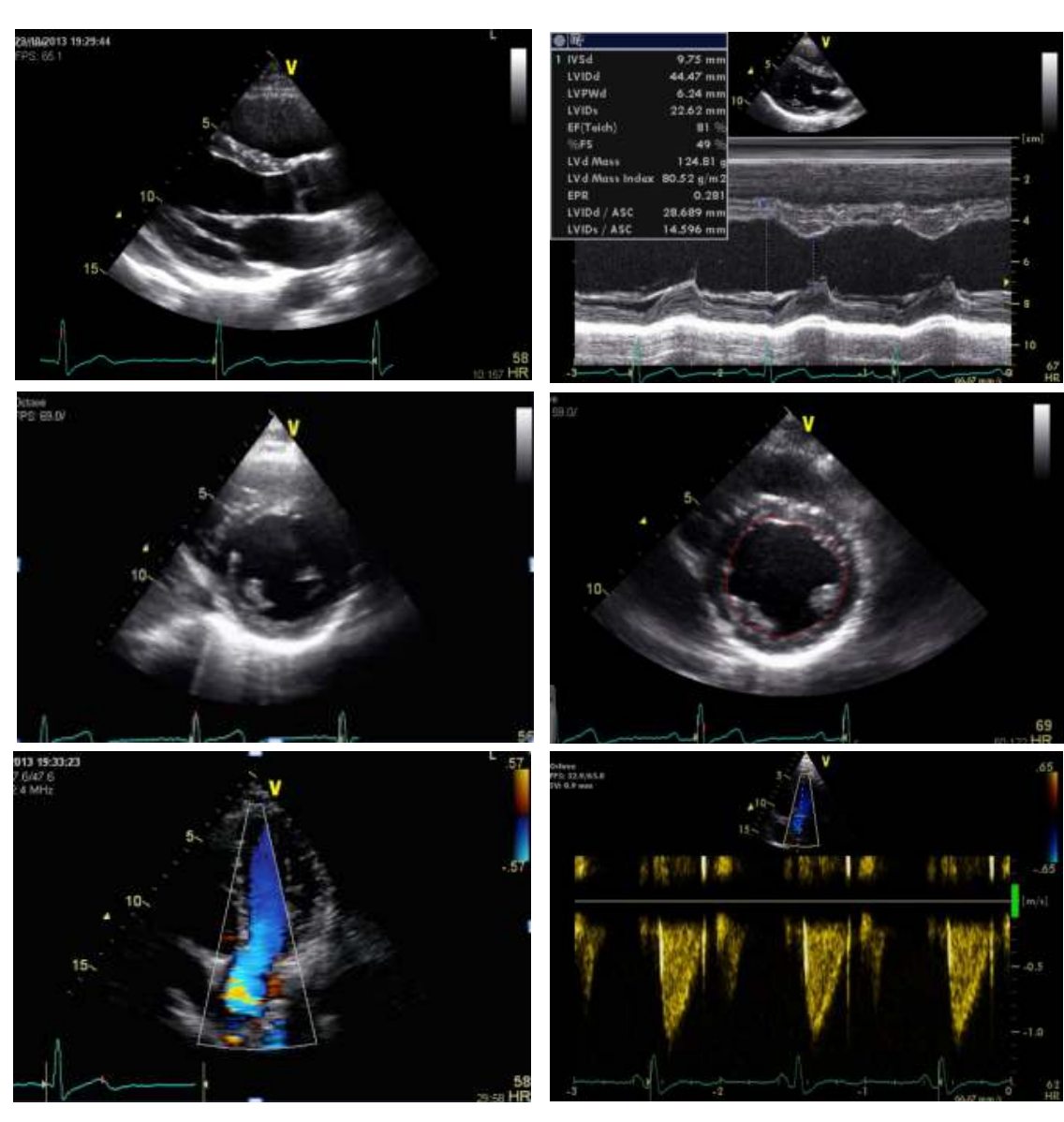

Results AND Discussion

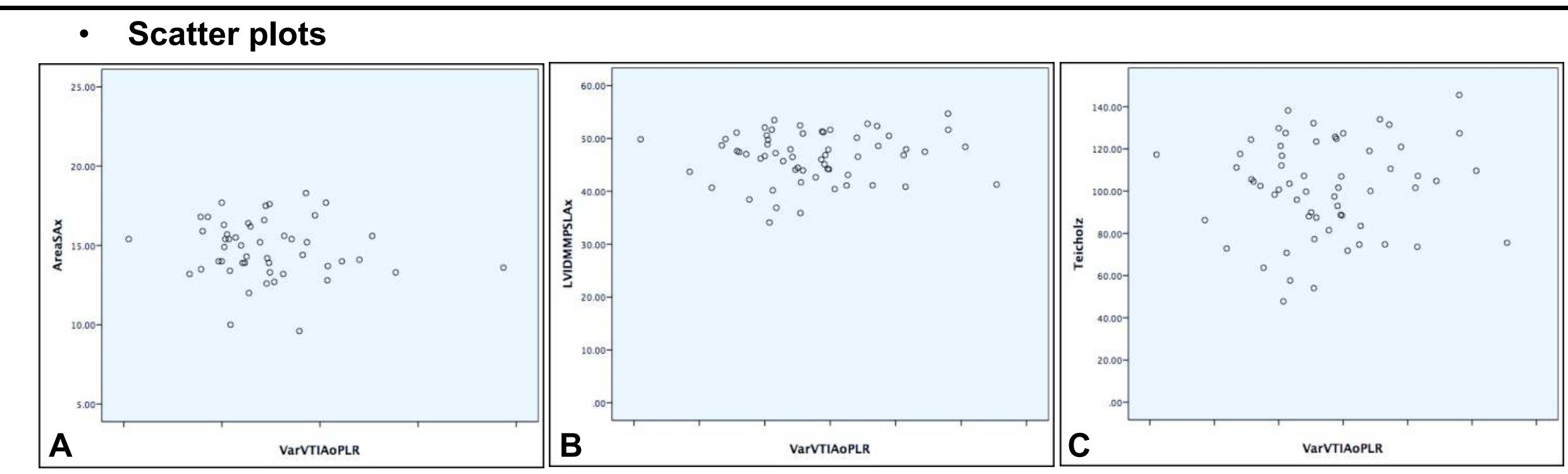

Figure 3 - Scatter plots: A- telediastolic area of the LV (at papillary muscles level) in PSSAx versus $\triangle V_{T I}{ }_{A o} P L R$; B- telediastolic diameter of the LV on M-mode in PSLAx versus $\triangle V T I_{A 0} P L R ; C$ - telediastolic volume of the LV (Teicholz formula) versus $\triangle \mathrm{VTI}_{\mathrm{AO}} \mathrm{PLR}$

- Correlation coefficients

\begin{tabular}{|c|c|c|c|}
\hline Variable & $\mathbf{N}$ & \multicolumn{2}{|c|}{ Correlation with $\mathbf{\Delta \mathbf { V T I } _ { \text { Ao } } \text { PLR }}$} \\
\hline $\begin{array}{c}\text { Pearson's corr. } \\
\text { coefficient }\end{array}$ & $\begin{array}{c}p \text {-value for } \\
\text { Pearson's corr. } \\
\text { coefficient }\end{array}$ \\
\hline LV $_{\text {Area Pap }}$ & 53 & 0,021 & 0,881 \\
\hline Musc PSSAx & & $-0,033$ & 0,800 \\
\hline TD $_{\text {LV PSLAx }}$ & 62 & 0,018 & 0,891 \\
\hline TDV $_{\text {LV Teicholz }}$ & 62 & & \\
\hline
\end{tabular}

Table 1 - Pearson's correlation coefficient analyzing the relation between telediastolic dimensions of the $\mathrm{LV}$ and $\triangle \mathrm{VTI}_{\mathrm{Ao}}$ PLR.

\section{- Mann-Whitney test}

\begin{tabular}{|c|c|c|c|}
\hline Variable & $\mathbf{N}$ & $\begin{array}{c}\text { p-value (distribution of the variable } \\
\text { between fluid responders and non- } \\
\text { responders) }\end{array}$ \\
\hline \begin{tabular}{c}
\hline$V_{\text {Area Pap Musc }}$ \\
PSSAx
\end{tabular} & 53 & 0,978 & $\Delta \mathrm{VTI}_{\text {Ao }}$ PLR $\geq 15 \%$ \\
\hline TD $_{\text {LV }}$ PSLAx & 62 & 0,926 & 0,859 \\
\hline TDV $_{\text {LV Teicholz }}$ & 62 & 0,926 & 0,337 \\
\hline
\end{tabular}

Table 2 - Mann-Whitney test results comparing the distribution of different telediastolic dimensions in fluidresponsive and non-fluid responsive individuals
Does a same preload necessarily imply the same stroke volume? And does that imply a similar position in the Frank-Starling curve?

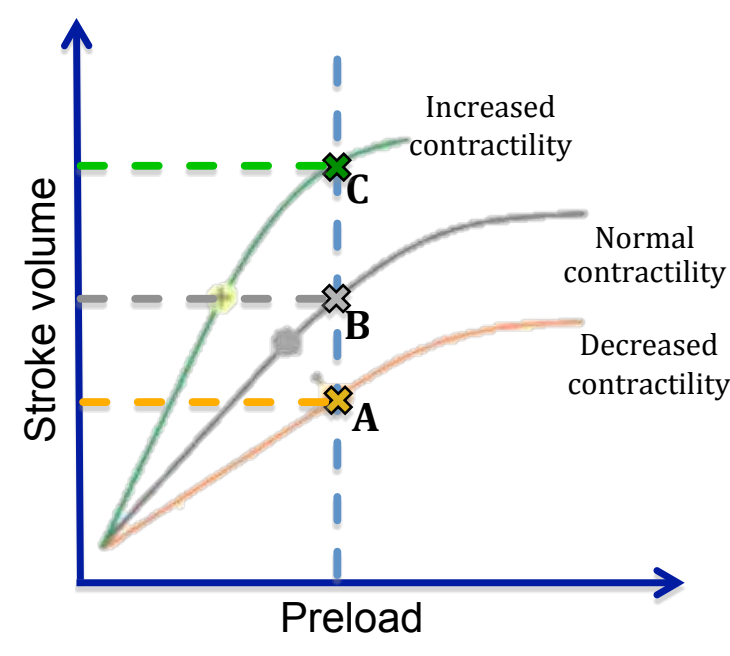

Figure 4 - Different Frank-Starling curves in the same individual ${ }^{1}$.

\section{Conclusions:}

- Although several studies have emphasized the role of dynamic preload indices and decreased enthusiasm for static ones such as telediastolic dimensions, they are still used clinically;

- The present study, however, cannot find a statistically significant relation between these and the validated indices of preload responsiveness for patients breathing spontaneously, which would advise against their use in routine practice;

- It should however be stated that none of our volunteers had extreme deviations in telediastolic values, which consequently does not allow us to infer as to the predictive value of very small dimensions in critical, haemodynamically unstable patients. Further studies are advised to further clarify the matter in these particular circumstances.

\section{References:}

I. Alves DR. Avaliação ecocardiográfica da influência do jejum na resposta a um aumento reversível da pré-carga [Dissertation]. Lisboa: Escola Superior de Tecnologia da Saúde de Lisboa/Instituto Politécnico de Lisboa; Faculdade de Medicina da Universidade de Lisboa; 2014.

2. Renner J, Scholz J, Bein B. Monitoring fluid therapy. Best Practice \& Research Clinical

Anaesthesiology. 2009;23(2):|159-| 7 |

3. Ramos FJS, Azevedo LCP. Assessment of fluid responsiveness in patients under spontaneous breathing activity. Rev Bras Ter Intensiva. 2009;21:212-218 